\title{
The significance of lifeworld and the case of hospice
}

\author{
Lisbeth Thoresen - Trygve Wyller • \\ Kristin Heggen
}

Published online: 13 November 2010

(c) The Author(s) 2010. This article is published with open access at Springerlink.com

\begin{abstract}
Questions on what it means to live and die well are raised and discussed in the hospice movement. A phenomenological lifeworld perspective may help professionals to be aware of meaningful and important dimensions in the lives of persons close to death. Lifeworld is not an abstract philosophical term, but rather the opposite. Lifeworld is about everyday, common life in all its aspects. In the writings of Cicely Saunders, known as the founder of the modern hospice movement, facets of lifeworld are presented as important elements in caring for dying patients. Palliative care and palliative medicine today are, in many ways, replacing hospices. This represents not only a change in name, but also in the main focus. Hospice care was originally very much about providing support and comfort for, and interactions with the patients. Improved medical knowledge today means improved symptomatic palliation, but also time and resources spent in other ways than before. Observations from a Nordic hospice ward indicate that seriously ill and dying persons spend much time on their own. Different aspects of lifeworld and intersubjectivity in the dying persons' room is presented and discussed.
\end{abstract}

\footnotetext{
L. Thoresen $(\bowtie)$

Faculty of Health Sciences, Vestfold University College, P.O.Box 2243, 3101 Tønsberg, Norway

e-mail: Lisbeth.Thoresen@hive.no

T. Wyller

Faculty of Theology, University of Oslo, Oslo, Norway

K. Heggen

Faculty of Medicine, University of Oslo, Oslo, Norway
}

Keywords Lifeworld · Hospice $\cdot$ Palliative care $\cdot$ Ethics in end-of-life-care $\cdot$ Evidence-based

\section{Introduction}

'A life well lived'. Walking between gravestones in an English graveyard some time ago, my ${ }^{1}$ eyes fell on this inscription. A woman was buried there; she died at a good old age. I was touched by the inscription, and I have continued to think about it. Perhaps this is a common gravestone inscription in England, but to me, as a Norwegian, it presented something new and different. The few words made me wonder about the woman's life-what it had been like, what she had experienced and what she had been through. Was 'a life well lived' her wish for the inscription, or was it how her relatives judged her life? 'Well lived' touched me, not because it made me think about a very special or interesting life, filled with magnificent events, but because the inscription on a plain gravestone in a windswept graveyard made me think about making use of life's opportunities. It was not a question about being able to cope with life, but of living life to the full. The words 'well lived' made me think about a life that had been meaningful and fulfilled, in one way or another, within the basic dimensions and borders of life. Dimensions such as sociality, time, space and embodiment represent something fundamental and common to all lives, something that opens life up to us, something that contains possibilities, but also ambiguity and restrictions. How the old woman had lived and what she had achieved in time and space, and how and to whom she had been connected, I will never know.

\footnotetext{
$\overline{1 \text { First author. }}$
} 
What a life well lived, or a good life actually means has been a philosophical issue through history. In this paper, the focus is on the end of life and especially on end-of-life care in hospices. Questions and reflections on what it means to live well and to die well have been raised and discussed in the hospice movement since the 1960's and 1970 's. In this paper we present a phenomenological perspective on end-of-life care in hospice. Phenomenology offers a variety of philosophical thinking and discussions. We find that it is important to consider hospice care with the phenomenological concept of lifeworld. One may say that lifeworld sums up the essence of phenomenology, which is to revive our living contact with reality (Moran 2000). Reality is the experienced world, the world as it is given and experienced by each one of us. The world as given means that the world is already there before us. Prior to our thinking of life and of the world, there are already grounded dimensions in life which form our lives and which we cannot escape; we live and die as embodied subjects, and we are always connected to the world and to others. Lifeworld is not an abstract philosophical concept, but rather the opposite; human life is concrete and meaningful, and the subject is intimately tied to the world, to concrete life (Moran 2000; Finlay 2009). We normally take these given life structures for granted; we do not often think about them (Moran 2000; Bengtsson 2006). Nevertheless, we believe that in reflecting on what a life well lived and well ended means, or what it consists of, the concept of lifeworld is significant because it reminds us about something already given. In developing knowledge on end-of-life care, we find it necessary to ask what kind of knowledge, meaning and normativity is already present in the life of the person who is dying. What Dahlberg et al. (2009) and Todres et al. (2007) call the human-world intimacy reminds us of grounded and deeply meaningful structures in life and the importance of making these visible (Martinsen and Eriksson 2009).

The goal of this paper is to explore more closely connectedness and relations as grounded and deeply meaningful structures in hospice philosophy and contemporary hospice practice. We will point to two reasons why we find these to be important issues to focus: in medicine and nursing, the request for evidence-based knowledge and practice is strong. According to Husserl, there is already evidence in the world we live in, in subjective and intersubjective living (Moran 2000). There are aspects of life that are visible, such as social life and relations, but which also carry an invisible, deeply important meaning (Dahlberg 2006). Making the grounded structures more explicit may help us to see their importance. The meaning embedded in every person's lifeworld, and in the relation between us, gives lifeworld an ethical and normative impact. There is an ethical source in the connectedness which implies that it is essential to be aware of the social dimensions of life (Wyller and Heimbrock 2010). We analyse how connectedness is described in parts of the extensive writings of Cicely Saunders, who is recognized as the founder of the modern hospice movement (Clark 2004; Clark et al. 2005). We also ask how the intersubjective life of the patient is attended to and realised in contemporary hospice practice. The question will be answered and discussed by describing some observations made by the first author in a Nordic hospice ward.

We start with a short section on the phenomenological theory on lifeworld.

\section{Lifeworld}

Phenomenology is characterized as a renewal of philosophy through its preoccupation with the physical, concrete life and living (Moran 2000). Lifeworld was developed as part of Edmund Husserl's scientific critique against scientism, rationalism and objectivism. According to Husserl, we tend to accept scientific knowledge as neutral, real and true. We tend to think that there is a reality out there, an objective truth, independent of history, culture and subjectivity. This is such a normal way of acknowledging scientific knowledge that Husserl labelled this "the natural attitude", an attitude present in theories as well as in everyday living. Husserl was clearly critical of such a scientific view of the world, and he describes naturalism as a "philosophical absolutising" (Moran 2000:143). What seemed neglected is that there is always a human factor in all human activity, including professional nursing, scientific work and the development of scientific and evidence based knowledge.

Lifeworld is not an abstract concept, but something very real and close to us. Lifeworld is our daily life; the world we live in here and now. It is what we take for granted, what we do not question or reflect upon, but rather, live. We live bodily, physically and practically, and we live with others. Lifeworld is a shared and meaningful world (Zahavi 2003; Schutz 2005). Before we start to think about the world and about everything going on around us, we must assume the world is already structured, shaped and meaningful. This is what Schutz calls common sense thinking (Schutz 2005).

The subject, be it a researcher, a nurse, a patient or a little child, is a non-questioning part of the lifeworld. The nurse and the patient are bodily, socially and culturally in the world. One cannot escape or live outside lifeworld; we are bound to subjectivity. This means that there are no absolute zero from where we can explore lifeworld, because we are already part of it as researchers and writers, and we always experience, perceive or explore from a 
perspective (Bengtsson 2006; Dahlberg 2006; Thoresen 2010).

\section{Hospice: an introduction}

The modern hospice movement seems to have become synonymous with particular places and ways of dying well (Clark et al. 2005). The development of hospices as places of a specific caring philosophy, and concrete attitudes and practices towards dying patients, is well described by Clark and others (Clark and Seymour 1999; Thoresen 2001; Clark 2002; Clark et al. 2005). What becomes clear from historical descriptions is that hospices as representing a modern philosophy of terminal care are closely linked to Cicely Saunders (1918-2005). We know that from the early start, others were involved in the hospice movement, both professionals as well as 'lay' people, but it was Saunders who actively developed what was to become hospice philosophy from around 1947 (Clark et al. 2005). This means that we are tracing the first steps back more than 60 years. When reading Saunders' writings today, it should not be forgotten that we are engaging with historical texts, written in the context of a specific time, society, culture and health care system. What we also find to be interesting from a phenomenological point of view is how Saunders biography and especially her relationships with certain patients came to colour and influence the development of hospice. Saunders, initially trained as a nurse and a social worker, became aware of the anxieties and sorrows surrounding death when she got to know David Tasma, a relatively young Polish Jew (Saunders and Kastenbaum 1997). As a professional carer, she followed him through his last stages of life. They developed a close friendship, and, to Saunders, the experiences and insights that grew from the friendship became the basis for what was to become the hospice movement. Tasma felt let down by society, by illness and by himself, and is described as an unhappy man. Among other themes, Tasma and Saunders discussed the possibility of creating special places or homes for patients who were close to death. The story of David Tasma and especially the fact that he left Saunders some money in his will "to be a window in your home" (Saunders and Kastenbaum 1997:4), has become a 'creation' narrative, retold many times by Saunders herself. After her experiences with Tasma, Saunders was advised to read medicine if she wanted to contribute to changes in contemporary practice and attitudes towards death and dying. She followed this advice, and after finishing her medical studies, Saunders started to work as a doctor at St. Joseph's Hospice in London. Here, she "transformed the ward" (Saunders 1996:1599) by introducing morphine on a regular basis and by creating medication routines and a report system. Nevertheless, perhaps the fact that Saunders spent hours listening to the patients, to their life stories, to their loss and joy, and to the narratives of their serious illnesses was what really mattered. Through patients' stories, Saunders understood that dying patients often felt themselves abandoned by society, doctors and nurses, and often by friends and family (Saunders 1984, 1996; Clark 1998). In a time (post-Second World War) when medicine developed rapidly, the main goal was treatment and rehabilitation, and dying had become perceived as a failure (Clark 1999a), and as something almost shameful (Saunders 1998). In the UK, dying patients were cared for very badly in some hospitals. We are told that they did not receive proper medical treatment, and they were often hidden in side rooms, away from the more active parts of the hospital. Patients received medical treatment, but no care for distress. Even if health care was Saunders's professional field, she found it important to try to influence the British culture and ideas on death and dying, and she often raised her voice in the public sphere to point to the time before death as an important and meaningful time for all involved.

The last 15-20 years has seen a growing interest in endof-life care, in all Scandinavian countries, the rest of Europe and the world. Today, the name and concept of hospice is often replaced with the term palliative (Clark and Seymour 1999). Palliative teams, palliative wards and even palliative beds are offered at different levels in public health care. For different reasons, some hospitals and wards still cling to the original hospice name. The change from hospice to palliative care and medicine has implied much more than just a new name. The first hospices offered a special room or place to stay near the end of life, when curative medical treatment was no longer possible. Today, the transition between curative and palliative care is vague, and many patients die whilst still under active curative treatment. The cure is much more active and requires advanced techniques and skills. Improved palliation means that patients experience less painful symptoms, a development that most of us value. On the other hand, this is an improvement that requires a lot of resources and time, and one may ask if focus is moved from care to cure, even if the patient is dying. The changes and development in hospice and palliative care have been welcomed, but have also made some ask if core hospice values are lost or marginalized (Clark and Seymour 1999; Field 2007).

\section{Hospice: a modern philosophy}

When Cicely Saunders died in 2005, she had authored around 220 publications on hospices, and their philosophy and practice. There are different themes in her articles, and 
Saunders compared the process that created hospices with a kaleidoscope, putting together different demands that previously did not relate to each other (Saunders 2000). Even though different topics are described and discussed in Saunders' writings, there is also an obvious continuity in nearly all her publications (Saunders and Kastenbaum 1997); Saunders points to poor conditions for dying patients in contemporary health care (Clark and Seymour 1999), and the need for safe, homelike places and professionals who are skilled in taking care of the dying person (Saunders 1981, 1984). She discusses death as taboo in Western society, and she calls for a new openness about dying and death (Saunders 1998). Saunders points to the necessity of including relatives in the lives of dying persons, and the importance of total care, to relieve total pain. The concept of total pain is a key concept in hospice philosophy (Clark 1999b), developed by Saunders because of something she learned from a patient. The elderly woman described to Saunders how pain started in her back, "but now it seems that all of me is wrong" (Clark 1999b:733). The patient described her symptoms and worries, and how she was cared for by her husband and son, but nevertheless felt that everyone was against her. After pausing, the patient continued, "But it is wonderful to begin to feel safe again" (Clark 1999b:733). Saunders translated the story into other words; "Without any further questions she had talked of her mental as well as physical distress, of her social problems and of her spiritual need for security" (Clark 1999b:728). In an article, published later the same year, Saunders made use of the concept total pain. All of me is wrong has become total pain (Clark 1999b:728).

The social dimension which is part of total pain and total care is repeated and given attendance in many of Saunders writings. In her first publication (Saunders 1958), we can read about Mr. S., Mrs. A, Mrs. R. and Mr. H. Saunders describes each of the four patients in four individual parts in the article, beginning with Mr. S and ending with $\mathrm{Mr}$. $\mathrm{H}$. The first sentence in each description is more or less similar. The patient is presented by name (anonymous), age, diagnosis and a characteristic attribute: $\mathrm{Mr}$. $\mathrm{H}$. is an Irishman; the other three patients are an "educated and intelligent housewife", a "housewife with five children", and a "publishing manager and preacher of atheism at Hyde Park Corner". From the very beginning of each case study, Saunders reminds the reader that patients are more than an interesting medical diagnosis. Patients are subjects, connected or intersubjective related to others through family, friends, work, religion, traditions, interests, nationality and so on. In a moving article from 1961 called A patient, Saunders describes in detail the story of Mrs. G., a woman and a patient she knew for 7 years. We will not discuss all the aspects of this story, what is relevant here is how Saunders sums up the things that brought Mrs. G. through; first of all, people (Saunders 1961). Saunders describes the patient's husband and mother, friends, nurses and doctors, what they meant to Mrs. G. and how they got her 'through'.

According to Saunders, the greatest sorrow of a dying patient was the ending of relations and feeling useless (Saunders 1984). The dying person needed recognition, attention, someone present beside him or her, someone willing to watch with me (Saunders 1978). What brought meaning to patients close to death, but also to relatives and professionals, seemed to be some sense of community or belonging (Saunders 1981). David Tasma's expressed need for a home for the dying, and the need for inclusion, community and common life is a distinct part of hospice philosophy (Saunders 1999; Thoresen 2001). Dying patients should not be hidden away behind curtains or left alone (Saunders 1981). It is interesting to see how Saunders defines religion as a "field of relationships of one person to another, commitment in the context of a common life" (Schoenberg et al. 1972). Saunders argued, that if we want to help others in their struggle to find meaning, we need to build bridges between us, and be willing to watch with the dying patient (Sykes and Saunders 1993). One may argue that in Saunders' writing, there are signs of an existing bridge because Saunders repeatedly reminds us about the fact that we all share the threat of death; it is a part of human life, it is something that we all have in common.

\section{Hospice today: an empirical study}

From reading Saunders' publications, we are left with the impression that patients were listened to, bringing the language, the narratives and phenomena of everyday life into the world of medicine and professional caring. More precisely, this is how Cicely Saunders describes what she did, and what she thought was the best way of getting to know the patients' needs. This became a normative quest; that one should learn from patients. One doctor, visiting St. Christopher's Hospice in 1970, tells how a chair was seen as an important piece of equipment on the ward rounds, because it was where one could sit down at eye-level with the patient and talk (Clark et al. 2005). Based on observations in a hospice ward of today, there are reasons to ask if the chair by the patient's bed still holds a vital position.

The observations and participant observations were part of a doctoral study, and took place in a Nordic hospice ward. $^{2}$ Trained as a nurse myself, I was allowed to follow and be an assistant to seven hospice nurses in their work with 20 patients, all staying in single-bed rooms. The main

\footnotetext{
${ }^{2}$ The study has been approved by the National Research Ethics Committee.
} 
goal of the four-month long field study was to gain direct data and knowledge of hospice nurses' practice towards their patients. This means that the focus of the study was on how nurses acted, talked and behaved when providing patient care, and how they reflected and talked to me about their caring work. I took part in conversations with patients in 'natural' situations, but patients were not interviewed. As far as I possibly could, I was aware of my self as a researcher subject, and of intentionality and involvement in the world also as an observer. I see the importance in scientific work of trying to "slacken the intentional threads which attach us to the world and thus bring them to our notice" (Merleau-Ponty 1962:xv), which is a challenging task. This make me aware of the fact that the following descriptions are small parts of a larger picture, and that the meaning given to the observations always can be challenged and discussed (Dahlberg 2006).

The ward is part of a hospice clinic in a larger town in one of the Nordic countries. It has existed for around 20 years, and has its roots in the hospice movement. Patients were mostly referred to the hospice ward by their doctor, and were prioritised after the following criteria: (1) Young patients with life-threatening diagnoses. (2) Patients with life-threatening diagnoses living on their own. At the time of the field study, the average stay in the ward was 30 days. The palliative team consists of nurses, enrolled nurses, doctors, chaplain, social worker and physiotherapist. The ward was, in many ways, a realization of Saunders' idea about creating rooms for common life, for being with others. Hospice values like these were expressed on the ward's homepage on the internet and in strategic documents and reports, and were visible in nice and inviting interiors in the hospice common rooms. Bright colours, comfortable and fine furniture, art, fresh flowers, tablecloths and lit candles invited patients and relatives to enter the room, occupy it, and to be there with others. The living room was not a room for solitude and privacy, but for social relations with others. Here, patients could feel at home, feel safe and comforted. The paradox was that these rooms were more or less empty through the days, weeks and months that I made observations. On some days, during lunch and dinner, a group of 2-4 patients would gather around the nicely laid table to share a meal. As soon as the meal was over, the patients would retire to their rooms. The main impression was that patients did not seek comfort in the company of others, but spent nearly all their time on their own.

The absence of patients in the common room became obvious in an early phase of the observation period. I spent the first 8-10 days in the ward, observing from a chair in the corridor, the living room and the conservatory. I did not enter patient's room until after the first 2 weeks of the observation period. From the chair I could smell, hear, watch, be aware of and wonder what was going on around me. There was busy times and quiet hours, there were staff walking between different rooms, some relatives passing slowly on their way to visit a wife or a friend. Patients were more or less absent. One or perhaps two might pass during the hours, but the main impression was that common rooms were patient free areas.

This was because patients spent nearly all time on their own in their rooms. This was confirmed when I started to follow the nurses into the patients. Of course relatives were visiting; some of them spent many hours with the patient. Including family and friends in the situation around the seriously ill patient is a core issue in hospice care. What surprised me was how many of the patients who actually spent hours and hours in their own company. Often, when entering the room, the patient was in bed and alone. The nurse or other parts of the staff looked after the patient, and they carried out different tasks, but they seldom had time to sit down and be with the patient. As described earlier, hospice has gone through major development and changes, and it is easy to explain the patient in the bed on his own as a result of this. A new lead clinician had declared that the hospice should offer active palliative care. This implied intensive medical treatment, more medical investigations, and frequent use of feeding tubes. Better symptomatic treatment is valuable and needed. On the other hand, extended medicalization takes a lot of time and attention. I observed how nurses could spend 1 hour on preparing medicine for one patient, then half an hour or even more in administering it. I hardly ever observed any of the nurses attending a patient's room without carrying medicine or objects relating to treatment. Spending time with patients without a goal or purpose was rare as far as I could see. According to the nurses, patients seemed to be more poorly when admitted to the hospice than previous patients had been, which meant that they needed more help and care. Some years ago, the nurses would take patients out for a walk or to visit a café, but this does not happen nowadays. It is a paradox that even if the patients admitted were more poorly than earlier, patients were frequently discharged to their own home or to residential homes for elderly persons. To make the stay at home possible, nurses spend much more time on the phone to plan care properly.

\section{Discussion}

It is not a straightforward task to compare hospice philosophy, which is very ideological and normative, with hospice practice, especially when it is observed in a country, time and context different to that in which it originated. At the same time, looking both backwards and towards the present, it is possible to point to some obvious 
changes in end-of-life care. Cicely Saunders was aware of the social dimension of total pain; being with others brings a sense of belonging and comfort. Creating places where patients, relatives, friends, staff and locals could meet and be together became a central part of hospice philosophy. Based on a study from a Nordic hospice ward, we find that sociality is still valued in official documents and in the ward's interior. Total care or holistic care is a main concept; in this paper, we ask if there is a gap between caring concepts and values, and the patient who spends a lot of time on his/her own. There may be some more or less obvious reasons for this. There is no doubt that end-of-life care today is very much about palliative medical treatment and care. The medical improvements are in many ways self-legitimated, and very few will ask if there are any side effects of this. Increasing numbers of patients and healthcare systems under economic pressure also indicate the need for efficiency in all levels and parts of health-care practice. This means evidence-based practice is now seen as equivalent to best and effective practice. As previously stated, it is difficult to challenge such changes and developments, because improved knowledge means fewer distressing symptoms. We believe that the impression of seriously ill and dying persons spending much of their time alone is connected to the medicalization of palliative care, but also to demands for more care for less money. Staff members are busy, and they have less time for each patient. Still, there are other questions to be asked about these observations. Why do patients not attend common room facilities more frequently, and why is it that some patients receive very few visitors? The answer may be that patients are too ill to leave their room, or that, given the fact that an increasing number of people in Western society live alone, it may be that we are more used to, and even prefer, being alone. Perhaps descriptions such as 'frequently' and 'few' are problematic, because they are inaccurate and relative. How many visitors for how many hours, and how many patients sitting in the chairs in the living room would meet the normative quest from Saunders on community and belonging? At what level does medical treatment that takes time and resources become a problem and begin to challenge the original hospice values? What makes a hospice a hospice? During the observation period, the nurses conveyed their uncertainty around this many times, asking if the hospice ward was still a hospice. Their grounds for asking this were more or less the same as the reasons the study gave.

Is the concept of lifeworld useful when it comes to analysing and reflecting further on end of life care in hospice? We find the answer to be yes, most of all because lifeworld raises our attention towards what kind of knowledge and practice is present in hospice care, and it helps us to look for dimensions as connectedness and relations in hospice practice. Lifeworld is not a normative concept in the sense that it will state how life should be lived, or about certain important values or ethical principles, and it is not a caring theory. Lifeworld is not helpful when it comes to what to do or how to communicate towards dying persons, or in developing manuals for nursing practice. It reminds us about something given before knowledge and practice is developed and structured. What is given is that we are connected to and responsible to each other; we are each other's world. Our lifeworlds touch upon each other and open a space between us. This is a space of possibilities, but also of risks and limitations. This is an ethical space. In health care and nursing, there seems to be a shift in what we find to be the source of normativity or sound ethical practice. This is a shift from seeing ethical principles and rules as the foundation to seeing the normative importance as already present in every (professional) encounter (Wyller et al. 2010), in every meeting and relation. We find that a lifeworld perspective helps us to see the other more clearly as a fellow human being, in what Dahlberg et al. (2009) and Todres et al. (2007) call human-world intimacy. We find that lifeworld points to a kind of evident knowledge, understood as grounded and deeply meaningful structures in life (Martinsen and Eriksson 2009).

\section{Conclusion}

The phenomenological concept of lifeworld is significant in developing reflections and knowledge on what it means to live well and to die well. This is because lifeworld is about concrete life and concrete structures in life. Structures or dimensions, like sociality, time, space and embodiment contain rich possibilities for living life to the full. These dimensions also make us vulnerable because life is limited and ambiguous. In this article, the focus has been on the dimension of sociality in end of life care; more closely on connectedness and relations in hospice care. In the writings of Cicely Saunders on caring for dying patients in hospice, we find that much attention is given to the value of being with others. No patient should face death on their own. The study presented in this article revealed that in a Nordic hospice ward this is still expressed as a main value and goal for hospice care. Observations challenged this picture; a main impression from the fieldwork period was that patients spent many hours every day without other persons company. We have discussed some reasons for this, like medicalization and the request for a more effective, evidence based palliative care. We find that there are reasons to ask if the development and medical improvements in palliative care and in hospice care may limit the possibilities for belonging and comfort that belongs to 
connectedness and relations. We hope that professionals will take this question seriously and reflect further on this.

Acknowledgments Our thanks to Professor of Hospice Studies Sheila Payne for insightful remarks and positive feedback.

Open Access This article is distributed under the terms of the Creative Commons Attribution Noncommercial License which permits any noncommercial use, distribution, and reproduction in any medium, provided the original author(s) and source are credited.

\section{References}

Bengtsson, J. 2006. Å forske i sykdoms- og pleieerfaringer: livsverdensfenomenologiske bidrag. Kristiansand: Høyskoleforlaget.

Clark, D. 1998. Originating a movement: Cicely Saunders and the development of St Christopher' s Hospice, 1957-1967. Mortality 3(1): 43-63.

Clark, D. 1999a. Cradle to the grave? Terminal care in the United Kingdom, 1948-1967. Mortality 4(3): 225-247.

Clark, D. 1999b. Total pain, disciplinary power and the body in the work of Cicely Saunders, 1958-1967. Social Science and Medicine 49: 727-736.

Clark, D. 2002. Cicely Saunders, founder of the hospice movement: Selected letters 1959-1999. Oxford: Oxford University Press.

Clark, D. 2004. History, gender and culture in the rise of palliative care. In Palliative care nursing, ed. S. Payne, J. Seymour, and C. Ingleton, 39-54. Maidenhead: Open university press.

Clark, D., and J. Seymour. 1999. Reflections on palliative care. Buckingham: Phil., Open University Press.

Clark, D., N. Small, M. Wright, M. Winslow, and N. Hughes. 2005. A bit of heaven for the few? An oral history of the modern hospice movement in the United Kingdom. Lancaster: Observatory Publications.

Dahlberg, K. 2006. 'The individual in the world-The world in the individual': Towards a human science phenomenology that includes the social world. The Indo-Pacific journal of phenomenology 6, Special Edition.

Dahlberg, K., L. Todres, and K. Galvin. 2009. Lifeworld-led healthcare is more than patient-led care: An existential view of well-being. Medicine, Health Care and Philosophy 12(3): 265-271.

Field, D. 2007. Palliative medicine and the medicalization of death. European Journal of Cancer Care 3(2): 58-62.

Finlay, L. 2009. Debating phenomenological research methods. Phenomenology \& Practice 3(1): 6-25.
Martinsen, K., and K. Eriksson. 2009. A se og a innse Om ulike former for evidens. Oslo: Akribe.

Merleau-Ponty, M. 1962. Phenomenology of perception. London: Routledge.

Moran, D. 2000. Introduction to phenomenology. London: Routledge.

Saunders, C. 1958. Dying of cancer. St Thomas Gazette 56(2): 37-47.

Saunders, C. 1961. A patient. Nursing Times, March 31, 394-397.

Saunders, C. 1978. The management of terminal disease. London: Edward Arnold.

Saunders, C. 1981. The hospice, it's meaning to patients and their physicians. Hospital Practice 16(6): 93-108.

Saunders, C. (1984) Facing Death. In: The Way, 296-304.

Saunders, C. 1996. Into the valley of the shadow of the death. A personal therapeutic journey. British Medical Journal 313: $1599-1601$.

Saunders, C. 1998. Foreword. In Oxford textbook of palliative medicine, ed. D. Doyle, G.W.C. Hanks, and N. MacDonald. Oxford: Oxford university press.

Saunders, C. 1999. Origins: International perspectives, then and now. The Hospice Journal 14(3/4): 1-7.

Saunders, C. 2000. The evolution of palliative care. Patient Education and Counselling 41: 7-13.

Saunders, C., and R. Kastenbaum. 1997. Hospice care on the international scene. New York: Springer Publishing Company.

Schoenberg, B., A.C. Carr, D. Peretz, and A.H. Kutscher (eds.). 1972. Psychosocial aspects of terminal care. New York: Columbia University Press.

Schutz, A. 2005. Hverdagslivets sociologi: en tekstsamling Tekstutvalg ved Boel Ulff-Møller. København: Hans Reitzel.

Sykes, N., and C. Saunders. 1993. The management of terminal malignant disease, 3rd ed. London: Edward Arnold.

Thoresen, L. 2001. Det gode liv - den gode d $\phi$ d: tekster av Cicely Saunders analysert og drøftet ut fra Charles Taylors filosofi om et godt og autentisk liv. Tønsberg: Høgskolen i Vestfold.

Thoresen, L. 2010. "I rather talk about football" a study on lifeworld in a hospice ward. In Perceiving the other Case studies and theories of respectful action, ed. T. Wyller, and H.-G. Heimbrock. Göttingen: Vandenhoeck \& Ruprecht.

Todres, L., K. Galvin, and K. Dahlberg. 2007. Lifeworld-led Healthcare: Revisiting a humanising philosophy that integrates emerging trends. Medicine, Health Care and Philosophy 10(1): 53-63.

Wyller, T., and H.-G. Heimbrock. 2010. Perceiving the other. Göttingen: Vandenhoeck \& Ruprecht.

Wyller, T., H.-G. Heimbrock, and P. Meyer. 2010. A demanding practice. In Perceiving the other, ed. T. Wyller, and H.-G. Heimbrock. Göttingen: Vandenhoeck \& Ruprecht.

Zahavi, D. 2003. Fanomenologi. Fredriksberg: Roskilde Universitetsforlag. 